\title{
A Review of Nano Particle Usage on Textile Material against Ultra Violet Radiation
}

\author{
Mohammed Asif Hossain 1", Moshiur Rahman² \\ ${ }^{1}$ Department of Textile Engineering, BGMEA University of Fashion \& Technology, Dhaka, Bangladesh \\ ${ }^{2}$ Department of Textile Engineering, Northern University Bangladesh, Dhaka, Bangladesh \\ Email: "asifbutex35@gmail.com
}

Received 3 September 2015; accepted 6 November 2015; published 9 November 2015

Copyright (C) 2015 by authors and Scientific Research Publishing Inc.

This work is licensed under the Creative Commons Attribution International License (CC BY).

http://creativecommons.org/licenses/by/4.0/

c) (i) Open Access

\begin{abstract}
Ultra violet radiation is detrimental to human skin and responsible for various skin diseases that is now worldwide growing concern for the people. Sun screen lotions, however, considered best possible solution but its temporary attachment didn't bring the real impact. The advancement of nano technology provides a number of techniques to introduce UV protected fabric by applying certain semi conductor metal oxide. So many researches have been carried out to coat the fabric using certain nano particles namely $\mathrm{ZnO}$ and $\mathrm{TiO}_{2}$ to improve the $\mathrm{UV}$ absorption capacity of material as well as increasing UPF value to protect the human skin which have been playing a significant role to provide UV protected clothing. This paper deals with the harmful impact of ultra violet radiation on human skin, UPF measurement method and UV protective finishing on textile material using nano $\mathrm{ZnO}$ and nano $\mathrm{TiO}_{2}$ particle.
\end{abstract}

\section{Keywords}

Ultra Violet Radiation, UPF, Nano ZnO, Nano $\mathrm{TiO}_{2}$

\section{Introduction}

Sunlight is one of the renewable energy sources and indespensible parts of living species. Sunlight consists of three rays depending on their variation of wave length: ultraviolet (UV) rays, visible light and infrared rays. Among these, ultraviolet rays have shortest wavelength and infrared rays have largest wavelength along with no visibility to eyes. The remaining one is the visible light in which wavelength ranges from $400 \mathrm{~nm}$ to $700 \mathrm{~nm}$ which includes all basic primary color, secondary color and tertiary color. Ultra violet rays can be divided into three categories: UVA, UVB and UVC in which each of the rays contains the wavelength 315 - $400 \mathrm{~nm}, 280$ -

${ }^{*}$ Corresponding author.

How to cite this paper: Hossain, M.A. and Rahman, M. (2015) A Review of Nano Particle Usage on Textile Material against Ultra Violet Radiation. Journal of Textile Science and Technology, 1, 93-100. http://dx.doi.org/10.4236/itst.2015.13010 
$315 \mathrm{~nm}$ and 100 - $280 \mathrm{~nm}$, respectively [1]. Among the total percentage amount of the incident sunlight on earth surface, the major percentage goes to visible light of having $50 \%$, infra red radiation at $45 \%$ and the remaining part is ultra violet radiation which is only $5 \%$ [2]. The intensity of ultra violet radiation depends on geographical location of the place, sun's altitude, season, time of the day as well as closely connected to the incident angle [2] [3]. Though only small amount of ultra violet radiation falls on the earth, it has adverse effect on human skin. UVR can cause cellular damage and photoaging of the skin and skin cancer by occurring DNA damage (formation of cyclobutane pyrimidine dimers), gene mutations, immunosuppression, oxidative stress and inflammatory responses [1] [4]. The radiation of UVA easily passes through the atmosphere and falls on the earth as the stratospheric ozone layer cannot filter those rays which in long-term exposure causes aging of the skin and induces immediate and persistent pigmentation (tanning) [1] [2]. Around 1\% - 10\% ultraviolet B radiation (UVB) comes on earth surface as the stratospheric ozone layer filter the major proportion of this rays. It is responsible causing sunburns, tanning, photoaging and skin cancer and has been found that UVB radiation is thousand times more effective in causing sunburn than UVA [1] [5]. It is a matter of luck that no UVC radiation comes on the earth as the whole proportion is filtered out by ozone layer which is more dangerous for skin damaging than that of UVA and UVC. The effectiveness of ozone layer is now under threat as the use of a particular gas called CFCs (Chloro-fluoro-Carbons) is increasing day by day which is likely to damage the ozone layer. Realizing the facts it is necessary to protect skin from over exposure of ultra violet radiation. To keep oneself save from ultra violet radiation it is required to avoid the UVR source but it is not the wise decision as our everyday's work related to combine integration of various outdoor activities. It is recommended that to wear a sunscreen, avoid going out in sunbath or cover up with clothing coated in ultraviolet protective agent [6] [7]. Sun screen has some disadvantages as it only absorbs UVB rays (280 - $315 \mathrm{~nm}$ ) but not UVA rays (315 - $400 \mathrm{~nm})$ and it needs to be attached to skin frequently. In recent years scientists on textile materials have paid a great attention on developing nano metal particle for coating on the fabric that can not only absorb the ultra violet radiation but also impart considerable improvement in physico chemical properties of fabric.

\section{Ultra Violet Radiation and Human Skin}

There is a certain relation between the wavelength and energy of the ultra violet radiation that can be derived by Planck's equation, $\mathrm{E}=\mathrm{h} v$ where $\mathrm{E}$ symbolizes the energy level, $\mathrm{h}$ represents the Planck's Constant which value is equal to $6.626 \times 10^{-34} \mathrm{~J} \cdot \mathrm{s}^{-1}$ and $v$ is the frequency of the electromagnetic wave. Here frequency is equal to $\mathrm{c} / \lambda$ where c refers the speed of light that equals to $3 \times 10^{8} \mathrm{~m} \cdot \mathrm{s}^{-1}$ and $\lambda$ is the wavelength of radiation. So the plank relation can be written as $E=h(c / \lambda)$; the smaller will be the wavelength of UV rays, the higher will be the energy level that is more harmful to living species. From this equation the order of potency can written as UVC > UVB > UVA. It is considered that Ultraviolet B radiation is more effective in causing sunburn than UVA [1] [8] [9].

Besides, skin is the longest part of human body comprised of three basic layers: Epidermis (outer), Dermis (middle) and Subcutaneous layer. Infra red radiation and visible light can penetrate all the three layer on the other hand UVA radiation can penetrate upto the layer of dermis while UVB radiation can penetrate upto the layer of epidermis as shown in Figure 1. It is clear that longest wavelength ultra violet radiation penetrate deeply than the ultra violet radiation of shortest wave length [2] [10].

However, 6 basic types of skin can be derived according to the sensitivity of light and tendency to pigmentation as shown in Table 1 , where the minimal erythemal dose vary along with skin type.

\section{Ultra Violet Protective Factor (UPF)}

Ultra violet protective factor represents the ultra violet radiation blocking capability of textile fabric to protect the skin. It is defined by the ratio of time required to show redness on the skin with and without protection, under the exposure of sun light [11]. The UPF can be calculated by following Equation (1):

$$
\mathrm{UPF}=\frac{\text { MED protected skin }}{\text { MED unprotected skin }}
$$

Here, MED symbolizes minimal erythemal dose or amount of radiant energy required to first pigmentation of skin after $22 \pm 2$ hours of continuous exposure. Table 2 shows the various UPF rating along with the category.

There are two methods using for measuring ultra violet protective factor, namely Vivo Method and Vitro Method. 


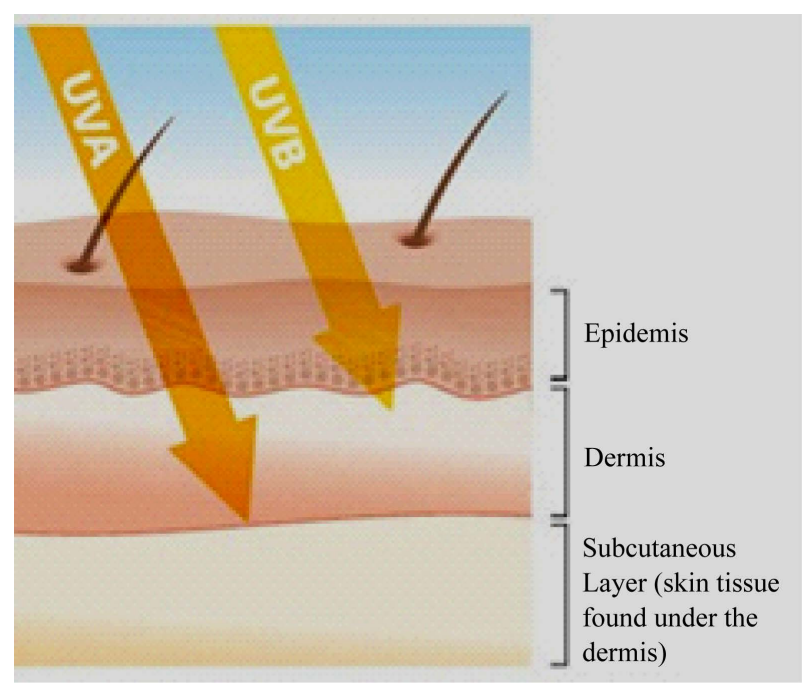

Figure 1. UV radiation and the skin [8].

Table 1. Effect of UV rays on different types of skin [3].

\begin{tabular}{cccl}
\hline $\begin{array}{c}\text { Skin type } \\
\text { (appearance unexposed) }\end{array}$ & $\begin{array}{c}\text { Critical dose } \\
\mathrm{mJ} / \mathrm{cm}^{2}\end{array}$ & $\begin{array}{c}\text { Self protection } \\
\text { time (min) }\end{array}$ & Risk level \\
\hline I. White & $15-30$ & $5-10$ & $\begin{array}{c}\text { Burns easily, has the highest risk of premature skin ageing and } \\
\text { greatest risk of developing skin cancer }\end{array}$ \\
II. White & $25-35$ & $8-12$ & Burn and only rarely tan \\
III. Brownish & $30-50$ & $10-15$ & Tan and occasionally burn \\
IV. Brown & $45-60$ & $15-20$ & Tan and occasionally burn \\
V. Brown & $60-100$ & $20-35$ & Sufficient levels of melanin and rarely burns, easily tan \\
VI. Dark brown-black & $100-200$ & $35-70$ & $\begin{array}{l}\text { Sufficient levels of melanin pigment provide protection. } \\
\text { Very rarely burns, easily tan. }\end{array}$ \\
\hline
\end{tabular}

Table 2. Ultra violet protective factor ratings [12].

\begin{tabular}{cccc}
\hline UPF range & Protection category & Effective UV-R transmission (\%) & UPF rating \\
\hline $15-24$ & Good & $6.7-4.2$ & 15,20 \\
$25-39$ & Very Good & $4.1-2.6$ & $25,30,35$ \\
$40-50,50+$ & Excellent & Less than 2.5 & $40,45,50,50+$ \\
\hline
\end{tabular}

\subsection{Vitro Method}

Direct and diffuse transmittance is an important factor for determining UV protectiveness of a textile material. Figure 2 represents how ultra violet light acts on textile material as there occur reflection, absorption, scattering and also direct transmission.

Spectrophotometers and spectroradiometers are useful device for the measurement of spectral radiation. Both these devices have the capability of taking scattered and transmittance radiation with the help of an integrated sphere that located behind the sample. Spectrophotometers fitted with double monochromators have wide dynamic range and high accuracy as well as deuterium or xenon arc lamps, are required to provide reference data [13]. To determine the in vitro UPF, the spectral irradiance (both source and transmitted spectrum) is weighted against the erythemal action spectrum [14] and the UPF is calculated as below:

$$
\mathrm{UPF}=\frac{\int E_{\lambda} S_{\lambda} T_{\lambda}}{\int E_{\lambda} S_{\lambda} T_{\lambda} \mathrm{d}_{\lambda}}
$$




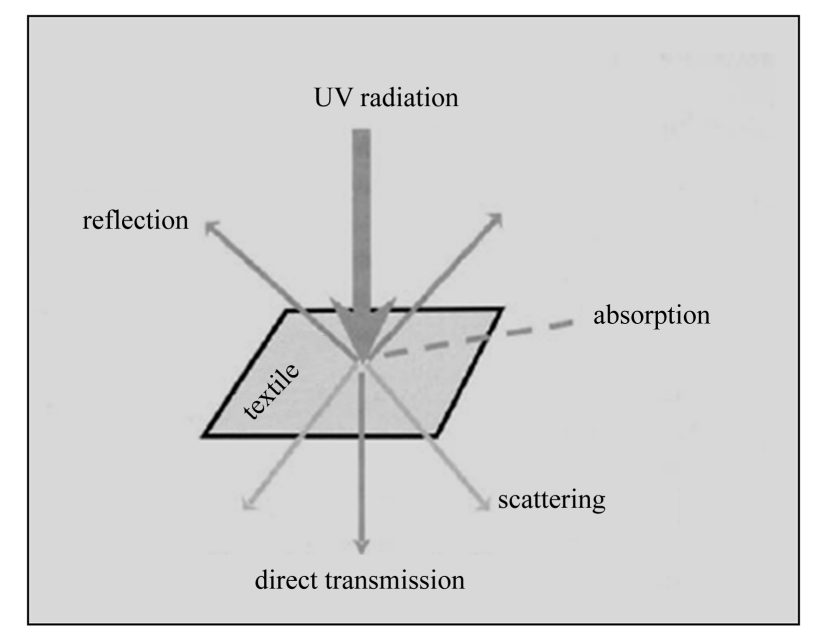

Figure 2. UV absorption, transmission and reflectance in textile material [13].

where $E_{\lambda}$ is the erythemal effectiveness of ultra violet radiation; $S_{\lambda}$, is the solar spectral irradiance in watts per meter squared; $T_{\lambda}$, is the spectral transmission of the sample, $\mathrm{d}_{\lambda}$ is the bandwidth in nanometers, $\lambda$ is the wavelength in nanometers, and the integrals are calculated over the wavelength range between $290-400 \mathrm{~nm}$.

\subsection{Vivo Method}

In this method a certain layer of thickness of lotion is applied on the back side of the test sample. Then the treated sample along with the unprotected skin is irradiated with standardized lamp that resemble the spectrum as closely as possible with that of sunlight.UPF is then determined from the quotient of the time it takes for skin reddening to occur with and without sunscreen [15]. Moreover, measurement of UPF by following this method is very much time consuming and the spectrum of light chosen for measurement is not similar to the sunlight as well as not very suitable for developing textile fabric against sun protection.

\section{UV Blocking Particle}

Over the past few years, nano technology has gained tremendous reputation as a key technology for making innovative products and increasing functional characteristic of material which was unforeseen earlier. There may be two types of UV blocking nano particle, one is organic UV blocker and another inorganic UB blocker. Inorganic UV blockers are considered best as it has no toxicity and chemically stable under long exposure of high temperature and UV [16]. Certain metal oxide particles such as $\mathrm{ZnO} \mathrm{TiO} 2, \mathrm{SiO}_{2}$ and $\mathrm{Al}_{2} \mathrm{O}_{3}$ [17] which all are inorganic compound as well as good UV blocker because these particles absorb the UV rays of equal energy or higher than their band gap. Among these $\mathrm{ZnO}$ [18]-[20] and $\mathrm{TiO}_{2}$ [16] [18] [19] [21] are commonly used. It has been found that nano sized $\mathrm{TiO}_{2}$ and $\mathrm{ZnO}$ have better absorption and scattering capability of ultraviolet radiation as the nano particle get larger surface area per unit volume and mass than the traditional particle [19]. According to Rayleigh's scattering theory the optimum nano particle size should be between 20 and $40 \mathrm{~nm}$ in case of scattering the Ultra Violet radiation between 200 and $400 \mathrm{~nm}$ [17].

\section{UV Protective Finish by Nano Particle}

In recent years UV protective finish by nano particle has been developed by applying various method and techniques. It is now the important potential areas of nano finishing application of nano sized semiconductor oxides such as $\mathrm{TiO}_{2}$ and $\mathrm{ZnO}$ as $\mathrm{UV}$ blocker [19].

\subsection{ZnO Nano Particle}

A Sivakumar et al. [19] synthesized $\mathrm{ZnO}$ nano particle using zinc acetate as precursor, by following wet chemical and sol-gel technique for UV protection of textiles to compare with untreated woven fabric. These nano par- 
ticles, which size of $9 \mathrm{~nm}$ were coated on to the cotton woven (plain weave, $40^{\mathrm{s}}$ count) fabric by adopting paddry-cure method and three different concentration level of nano $\mathrm{ZnO}$ solution: $1 \%, 1.5 \%$, and $2 \%$ were taken. The enhanced concentration of nano solution provided increasing UPF values as well as better UPF values for repeated wash.

Yadav et al. [20] investigated the effectiveness of nano sized $\mathrm{ZnO}$ particle comparing with bulk $\mathrm{ZnO}$ as ultraviolet protective agent. $\mathrm{ZnO}$ nano particles were prepared by wet chemical method using zinc nitrate and sodium hydroxide as precursor and soluble starch as solubilizing agent; the size of nano particle was $40 \mathrm{~nm}$. The coating was done by pad-dry-cure method where the padding solution containing $2 \% \mathrm{ZnO}$ and $1 \%$ acrylic binder; coating fabric was air dried and cured at $140^{\circ} \mathrm{C}$. UV absorption of nano-ZnO coated fabric was $75 \%$ which was higher than bulk $\mathrm{ZnO}$ coated fabric as well as improved tensile strength, air permeability and breaking strength.

S. Khatirvelu et al. [22] studied the improvements of UV blocking properties in cotton fabric and polyester/ cotton fabric using $\mathrm{ZnO}$ nano particles. In their research, synthesize of $\mathrm{ZnO}$ nano particle was done by using two methods; in one method $\mathrm{ZnCl}_{2}$ (minimum 98\%), $\mathrm{NaOH}$ (pellete minimum 99\%), 2-propanol (minimum 99.5\%) were used and the other method parameters were same like previous one but 1, 2 ethanediol (minimum 99.5\%) was used instead of water. Paricle size got $20 \mathrm{~nm}$ and $9 \mathrm{~nm}$ respectively for the two process. Two types of woven and knitted fabric, one was $100 \%$ cotton and another was 45:55 polyester/cotton, were used. The coating of nano-ZnO particle on the fabric was done on pad-dry method, both the fabrics were immersed in 2-propanol dispersion of $5 \%$ nano $\mathrm{ZnO}$ and then passed through the squeezer of padding mangle which was further followed by drying in a oven at $130^{\circ} \mathrm{C}$. That finishing process provided better UV blocking properties in case of woven fabric than that of knitted fabrics for both of the fabric construction. However, ZnO nano particle, reduced particle size was $9 \mathrm{~nm}$, synthesized by using 1, 2 ethanediol (minimum 99.5\%) showed comparatively higher protection against UV radiation.

Asma farook et al. [23] developed a method where Sol-gel based inorganic-organic hybrid polymers were modified with nano sized zinc oxide particles and applied on cotton (100\%) and cotton/polyester (65\%/35\%) fabrics. $\mathrm{ZnO}$ nano particle were produced by the suspension of precursor and the hydrolyse of that precursor whereas Zinc acetate and isopropanol were used to make precursor and lithium hydroxide was used to hydrolysis the precursor; average particle size of 30 - $60 \mathrm{~nm}$. Inorganic-organic hybrid polymers were 3-glycidyloxypropyltrimethoxysilane (GPTMS). GPTMS sol were prepared by dissolving $10 \mathrm{ml}$ GPTMS in $100 \mathrm{ml}$ isopropanol before hydrolysis using $1.22 \mathrm{ml}$ hydrochloric acid. Nano sized ZnO and GPTMS sol both were mixed and followed by further adding 1-methylimidazo as a catalyst for the cross-linking reaction of the GPTMS. Coating applied on both fabric by pad-cure method and $100 \%$ wet pick up was maintained in the padding process which further followed by curing at $130^{\circ} \mathrm{C}$. It was found that increasing concentration of $\mathrm{ZnO}$-sol uplifted the UPF value of cotton and cotton blend fabric. However, there was no effect on the UPF value of the fabric after the 5 washing cycles.

Becheri et al. [24] produced peptised $\mathrm{ZnO}$ nano particles from zinc chloride and sodium hydroxide solutions and applied them onto cotton and wool fabrics. The wool and cotton samples were immersed for 10 minutes in a 2-propanol dispersion of $\mathrm{ZnO}$ nanoparticles ( $5 \% \mathrm{w} / \mathrm{w}$ ), under gentle magnetic stirring. The clothes were then passed through the padder to remove the excess dispersion, and dried in an oven at $130^{\circ} \mathrm{C}$ for 15 minutes at atmospheric pressure. The UV transmittance of the cotton and wool fabric was reduced significantly. After 5 launderings, more than $50 \%$ of their initial amount remained on the fabric as the large conglomerates were removed from the fabric surface though the nano particles were not covalently attached to the fabric materials.

Vigneshwaran et al. [25] synthesized Zinc oxide-soluble starch nanocomposites (nano-ZnO) using water as a solvent and soluble starch as a stabilizer. We have successfully dispersed $\mathrm{ZnO}$ nanoparticles inside a soluble starch matrix using a simple water-based technique. The average size of the $\mathrm{ZnO}$ nanoparticles was estimated at $38 \pm 3 \mathrm{~nm}$. A fine-medium weight $100 \%$ cotton woven fabric (plain weave; $75.30 \mathrm{~g} \cdot \mathrm{m}^{-2}$; ends, $75 /$ inch; picks, 60/inch) was used in this study. Nano-ZnO was applied on the cotton using the "pad-dry-cure" method. The cotton fabric (size: $30 \mathrm{~cm} \times 30 \mathrm{~cm}$ ) was immersed in the nano-ZnO $(0.2,0.4,0.6,0.8$ or $1.0 \%)$ solution and acrylic binder (1\%) for 5 minutes and then it was passed through a padding mangle. After padding, the fabric was air-dried and then cured for 3 minutes at $140^{\circ} \mathrm{C}$ to polymerize the acrylic binder. The fabric was then immersed for 5 minutes in 2 gram per litre of sodium lauryl sulfate to remove unbound nano-ZnO. It was found that the nano-ZnO impregnated fabrics retained more than $80 \%$ efficiency of both antibacterial and UV-protection functions even after 25 wash cycles. 


\section{2. $\mathrm{TiO}_{2}$ Nano Particle}

Gouda et al. [16] synthesized Nano- $\mathrm{TiO}_{2}$, average size 5 - $10 \mathrm{~nm}$, via reduction of titanium tetrachloride using sodium borohydride in the presence of poly vinyl pyrrolidone as stabilizing agent. Nano- $\mathrm{TiO}_{2}$ was applied to cotton fabric sample using pad-dry-cure method. Padding solution was prepared as following; $1 \mathrm{~g}$ of nanoparticles was sonicated for 30 minutes with 98 gm water and $1 \mathrm{gm}$ of acrylic binder. 100\% wet pick-up was maintained for the fabric sample. Padded fabric sample was dried for 5 minutes at $80^{\circ} \mathrm{C}$ and then cured for 3 minutes at $140^{\circ} \mathrm{C}$. They found that $\mathrm{Nano}-\mathrm{TiO}_{2}$ loaded cotton fabric sample was durable to wash and it was very good UV-protection capacity as well as the maintained excellent antibacterial activity even after repeated 20 washing cycles.

Shalaby et al. [26] investigated a simple and economic approach for enhancing binding efficiency of $\mathrm{TiO}_{2}$ nanoparticles to PET fabrics based on applying the chemical activation method before loading PET fabrics with $\mathrm{TiO}_{2}$ nanoparticles by sol-gel method. $\mathrm{TiO}_{2}$ colloid solution was prepared by using titanium tetra isopropoxide, 2-propanol and concentrated $\mathrm{HNO}_{3}$. Alkali pre treated PET textiles samples were immersed in $\mathrm{TiO}_{2}$ colloidal solution, squeezed to the required pickup percent, dried in air at $220^{\circ} \mathrm{C}$ (room temperature) for 24 hours and then cured in an oven at $130^{\circ} \mathrm{C}$ for 15 minutes. The PET samples were then washed with distilled water to remove $\mathrm{TiO}_{2}$ particles that did not attach to the fabric surface. Their result exhibited outstanding antimicrobial activity and UV protection efficiency even after five washing cycles, indicating the excellent laundering durability.

Ugur et al. [27] applied anatase $\mathrm{TiO}_{2}$ nanoparticles (particle size $<25 \mathrm{~nm}$ ) on cationically modified woven cotton fabrics by the layer-by-layer molecular self-assembly technique. Positively charged cotton fabrics and were immersed into the following solutions alternately for 5 min periods: (a) the anionic $\mathrm{TiO}_{2}$ colloid solution; (b) the deionized water; (c) the cationic $\mathrm{TiO}_{2}$ colloid solution; (d) the deionized water and deposition cycle was repeated until 10- and 16-layer $\mathrm{TiO}_{2} / \mathrm{TiO}_{2}$ films were deposited on cotton fibers. Multilayer film coated cotton fabrics were dried at $60^{\circ} \mathrm{C}$ and cured at $130^{\circ} \mathrm{C}$ for 3 minutes. They found that, the UPF values were maintained same for both layers after 10 washing cycles, but after 20 washing cycles the UPF values decreased to 40 and 45 for 10- and 16-layer nano- $\mathrm{TiO}_{2}$ deposited cotton fabrics, respectively.

Li et al. [28] prepared Nano- $\mathrm{TiO}_{2}$ sol to coat on polyester fabric by using by sol-gel method in which which tetrabutyl titanate was used as precursor and ethanol was used as solvent. The average particle size of the nanometer particles is $23.3 \mathrm{~nm}$ ranging uniformly between $5 \mathrm{~nm}$ to $50 \mathrm{~nm}$. The plasma pretreated polyester fabrics dipped into the Nano- $\mathrm{TiO}_{2}$ sol, passed through the padder and then dry out under $80^{\circ} \mathrm{C}$. The process resulted in exceptional anti-ultraviolet performance with a phenomenal UPF ascendance reaching up to 50+ without influencing the breaking strength.

Xin et al. [29] studied a permanent UV protection treatment using thin films of sol-gel processed titania. A nanosol was prepared at room temperature by mixing titanium tetraisopropoxide (Aldrich, 97\%) with absolute ethanol (Riedel, 99.8\%) at pH 1 - 2. A thin layer of coating around $100 \mathrm{~nm}$ formed on the fiber surface. The results showed that the excellent ultra violet protection rating of the treated fabrics maintained even after 55 home launderings, indicating a high level of adhesion between the titania layer and the cotton.

Montazer et al. [30] used nano crystalline titanium dioxide to coat the wool fabric. They developed a method where $\mathrm{KMnO}_{4}$ treated scoured wool fabric at first immersed into ultrasonic bath containing three different concentration level and then dipped into impregnated bath containing cross-linking agent and sodium hypophosphite. The average particle size was $21 \mathrm{~nm}$. Treated samples were cured at $120^{\circ} \mathrm{C}$ for 2 minutes. Their research concluded that with increasing the amount of $\mathrm{TiO}_{2}$ on wool surface, protection against UV rays increased.

\subsection{Other Nano Particle Usage}

There are also some experiments have been carried out by using silver nano particle, $\mathrm{CeO}_{2}, \mathrm{SiO}_{2}$ as ultra viplet protective agent as well as maintaining multifunctional properties.

Shateri-Khalilabad et al. [31] developed a simple method by using silver nanoparticles (AgNPs) with a high deposition density were formed on the surface of cotton fabric through an alkali pre-activation followed by in situ reduction of silver nitrate. The Ag-coated fabric was then reacted with octyltriethoxysilane (OTES) to form a low surface energy layer on the fiber surface. The fabrics were characterized by ultraviolet-visible reflectance spectrophotometry, scanning electron microscopy (SEM), energy dispersive X-ray spectroscopy, and X-ray diffractometry. UV-blocking ability was measured using the AATCC method and the fabric also showed excellent 
UV-blocking with the ultraviolet protection factor of 266.01. The AgNPs with the average size of about $500 \mathrm{~nm}$ were formed, which uniformly covered the fiber surfaces. The obtained results from these experiments demonstrated the good durability of the finish against laundering.

Duan et al. [32] first treated the cotton fabrics with $\mathrm{CeO}_{2}$ sol and then modified with a layer of dodecafluoroheptyl-propyl-trimethoxylsilane (DFTMS). The as-prepared $\mathrm{CeO}_{2}$ sol was coated onto the cotton fabric sample by dip-pad-cure process. The cotton sample was first dipped into the $\mathrm{CeO}_{2}$ sol for 3 minutes and then padded with a two-roll laboratory padder giving a wet pick-up of $70 \%-80 \%$. Finally, the padded substrate was airdried for $20 \mathrm{~min}$ and cured at $170^{\circ} \mathrm{C}$ for 3 minutes. This process was repeated three times to form a dense film of $\mathrm{CeO}_{2}$ xerogel on cotton fabrics. The treated fabrics were then immersed in the ethanol solution of hydrolyzed DFTMS for 24 hours. They observed a significant transmittance decrease in the UV region, and transmission was reduced to nearly zero in the wavelength below $350 \mathrm{~nm}$, which indicates that the cotton fabric treated with $\mathrm{CeO}_{2}$ sol and hydrolyzed DFTMS may offer better protection from UV radiation than the pristine cotton fabric.

Wang et al. [33] investigated a method which involved the low-temperature preparation of ZnO seeds, hydrothermal growth of $\mathrm{ZnO}$ nanorods, bioinspired layer-by-layer deposition of a $\mathrm{SiO}_{2}$ shell on the surface of $\mathrm{ZnO}$ nanorods, and hydrophobic modification $\mathrm{SiO}_{2}$-coated $\mathrm{ZnO}$ nanorod array on the cotton textile The treated cotton textile was found to have a large UV protection factor (UPF = 101.51) together with UV-durable superhydrophobicity, as determined by contact-angle measurement under long-term UV irradiation.

\section{Conclusion}

There is no alternative option available to avoid ultra violet radiation that emits through sunlight. So, ultra violet protective finish on textile material achieved significant value on buyers specially those who are from warmer region of the world. Most of the investigations have been carried out in padding method to apply nano particles as better UPF value was obtained in almost all of the experiments on textile material. But exhaustion method in case of applying nano particle on textile substrate is still rare. Further research on this finishing process can bring out a significant change on applying method.

\section{References}

[1] Das, B.R. (2010) UV Radiation Protective Clothing. Open Textile Journal, 3, 14-21.

[2] Narayanan, D.L., Saladi, R.N. and Fox, J.L. (2010) Review: Ultraviolet Radiation and Skin Cancer. International Journal of Dermatology, 49, 978-986. http://dx.doi.org/10.1111/j.1365-4632.2010.04474.x

[3] Saravanan, D. (2007) UV Protection Textile Materials. AUTEX Research Journal, 7, 53-62.

[4] Meeran, S.M., Punathil, T. and Katiyar, S.K. (2008) IL-12 Deficiency Exacerbates Inflammatory Responses in UVIrradiated Skin and Skin Tumors. Journal of Investigative Dermatology, 128, 2716-2727. http://dx.doi.org/10.1038/jid.2008.140

[5] http://www.skincancer.org/prevention/uva-and-uvb/understanding-uva-and-uvb

[6] Davis, S., Capjack, L., Kerr, N. and Fedosejcvs, R. (1997) Clothing as Protection from Ultraviolet Radiation: Which Fabric Is Most Effective? International Journal of Dermatology, 36, 374-379. http://dx.doi.org/10.1046/j.1365-4362.1997.00046.x

[7] Mahler, H.I., Kulik, J.A., Gibbons, F.X., Gerrard, M. and Harrell, J. (2003) Effects of Appearance-Based Intervention on Sun Protection Intentions and Self-Reported Behaviors. Health Psychology, 22, 199. http://dx.doi.org/10.1037/0278-6133.22.2.199

[8] http://www.who.int/uv/faq/uvhealtfac/en/

[9] Soehnge, H., Ouhtit, A. and Ananthaswamy, O.N. (1997) Mechanisms of Induction of Skin Cancer by UV Radiation. Frontiers in Bioscience, 2, D538-D551.

[10] Achwal, W.B. (1997) Sun Protection Properties of Textile Substrates. Colourage, 44, 31-32.

[11] Perenich, T.A. (1998) Textiles as Preventive Measures for Skin Cancer. Colourage, 45, 71-73.

[12] http://www.rei.com/learn/xpert-advice/sun-protection.html

[13] Gambichler, T., Altmeyer, P. and Hoffmann, K. (2002) Comparison of Methods: Determination of UV Protection of Clothing. In: Dummer, R., Nestle, F.O. and Burg, G., Eds., Cancers of the Skin, Springer, Berlin Heidelberg, 55-61. http://dx.doi.org/10.1007/978-3-642-59410-6_8

[14] Matthes, R. (1998) Measurements of Optical Radiation Hazards. International Commission on Non-Ionizing Radiation 
Protection; International Commission on Illumination.

[15] Hilfiker, R., Kaufmann, W., Reinert, G. and Schmdt, E. (1996) Improving Sun Protection Factors of Fabrics by Applying UV-Absorbers. Textile Research Journal, 66, 61-70. http://dx.doi.org/10.1177/004051759606600201

[16] Gouda, M. and Aljaafari, A.I. (2012) Augmentation of Multifunctional Properties of Cellulosic Cotton Fabric Using Titanium Dioxide Nanoparticles. Advances in Nanoparticles, 1, 29-36. http://dx.doi.org/10.4236/anp.2012.13005

[17] Wong, Y.W.H., Yuen, C.W.M., Leung, M.Y.S., Ku, S.K.A. and Lam, H.L.I. (2006) Selected Applications of Nanotechnology in Textiles. AUTEX Research Journal, 6, 1-8.

[18] Tsuzuki, T. and Wang, X. (2010) Nanoparticle Coatings for UV Protective Textiles. Research Journal of Textile and Apparel, 14, 9-20.

[19] Sivakumar, A., Murugan, R., Sunderasan, K. and Periyasamy, S. (2013) UV Protection and Self Cleaning Finish for Cotton Fabric Using Metal Oxide Nanoparticles. Indian Journal of Fibre and Textile Research, 38, $285-292$.

[20] Yadav, A., Prasad, V., Kathe, A.A., Raj, S., Yadav, D., Sundaramoorthy, C. and Vigneshwaran, N. (2006) Functional Finishing in Cotton Fabrics Using Zinc Oxide Nanoparticles. Bulletin of Materials Science, 29, 641-645. http://dx.doi.org/10.1007/s12034-006-0017-y

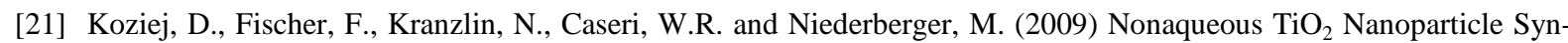
thesis: A Versatile Basis for the Fabrication of Self-Supporting, Transparent, and UV-Absorbing Composite Films. ACS Applied Materials \& Interfaces, 1, 1097-1104. http://dx.doi.org/10.1021/am9000584

[22] Kathirvelu, S., D’souza, L. and Dhurai, B. (2009) UV Protection Finishing of Textiles Using ZnO Nanoparticles. Indian Journal of Fibre \& Textile Research, 34, 267-273.

[23] Farouk, A., Textor, T., Schollmeyer, E., Tarbuk, A. and Grancacic, A.M. (2010) Sol-Gel-Derived Inorganic-Organic Hybrid Polymers Filled with ZnO Nanoparticles as an Ultraviolet Protection Finish for Textiles. Autex Research Journal, 10, 58-63.

[24] Becheri, A., Dürr, M., Nostro, P.L. and Baglioni, P. (2008) Synthesis and Characterization of Zinc Oxide Nanoparticles: Application to Textiles as UV-Absorbers. Journal of Nanoparticle Research, 10, 679-689. http://dx.doi.org/10.1007/s11051-007-9318-3

[25] Vigneshwaran, N., Kumar, S., Kathe, A.A., Varadarajan, P.V. and Prasad, V. (2006) Functional Finishing of Cotton Fabrics Using Zinc Oxide-Soluble Starch Nanocomposites. Nanotechnology, 17, 5087-5095. http://dx.doi.org/10.1088/0957-4484/17/20/008

[26] Shalaby, S.E., Abo El-Ola, S.M., AL-Blakocy, N.G., Beliakova, M.K. and Afify, H. (2013) Effect of Surface Activation Method of PET and PET/C Blended Fabrics on Its Functional Finishing with $\mathrm{TiO}_{2}$ Nanoparticles. Journal of Applied Sciences Research, 9, 1731-1742.

[27] Ugur, Ş.S., Sariişik, M. and Aktaş, A.H. (2010) The Fabrication of Nanocomposite Thin Films with $\mathrm{TiO}_{2} \mathrm{Nanopar}^{-}$ ticles by the Layer-by-Layer Deposition Method for Multifunctional Cotton Fabrics. Nanotechnology, 21, Article ID: 325603. http://dx.doi.org/10.1088/0957-4484/21/32/325603

[28] Li, H., Deng, H. and Zhao, J. (2009) Performance Research of Polyester Fabric Treated by Nano Titanium Dioxide (N ano- $\mathrm{TiO}_{2}$ ) Anti-Ultraviolet Finishing. International Journal of Chemistry, 1, 57. http://dx.doi.org/10.5539/ijc.v1n1p57

[29] Xin, J.H., Daoud, W.A. and Kong, Y.Y. (2004) A New Approach to UV-Blocking Treatment for Cotton Fabrics. Textile Research Journal, 74, 97-100. http://dx.doi.org/10.1177/004051750407400202

[30] Montazer, M. and Pakdel, E. (2010) Reducing Photoyellowing of Wool Using Nano $\mathrm{TiO}_{2}$. Photochemistry and Photobiology, 86, 255-260. http://dx.doi.org/10.1111/j.1751-1097.2009.00680.x

[31] Shateri-Khalilabad, M. and Yazdanshenas, M.E. (2013) Fabrication of Superhydrophobic, Antibacterial, and Ultraviolet-Blocking Cotton Fabric. Journal of the Textile Institute, 104, 861-869. http://dx.doi.org/10.1080/00405000.2012.761330

[32] Duan, W., Xie, A., Shen, Y., Wang, X., Wang, F., Zhang, Y. and Li, J. (2011) Fabrication of Superhydrophobic Cotton Fabrics with UV Protection Based on $\mathrm{CeO}_{2}$ Particles. Industrial \& Engineering Chemistry Research, 50, 4441-4445. http://dx.doi.org/10.1021/ie101924v

[33] Wang, L., Zhang, X., Li, B., Sun, P., Yang, J., Xu, H. and Liu, Y. (2011) Superhydrophobic and Ultraviolet-Blocking Cotton Textiles. ACS Applied Materials \& Interfaces, 3, 1277-1281. http://dx.doi.org/10.1021/am200083z 